\title{
SISTEM PENDUKUNG KEPUTUSAN PEMILIHAN SISWA PERTUKARAN PELAJAR DI SMAN 3 MALANG DENGAN METODE AHP TOPSIS
}

\author{
Lailatul Fitria $^{1}$, Dwi Puspitasari ${ }^{2}$, Yuri Ariyanto ${ }^{3}$ \\ ${ }^{1,2,3}$ Program Studi Teknik Informatika Jurusan Teknologi Informasi, Politeknik Negeri Malang \\ lailatul44@gmail.com, ${ }^{2}$ dwi_sti@yahoo.com, ${ }^{3}$ yuri.bjn@gmail.com
}

\begin{abstract}
Abstrak
Pertukaran pelajar di SMAN 3 Malang sudah dilakukan sejak beberapa tahun yang lalu. Namun permasalahan yang terjadi yaitu cara penilaian yang dilakukan masih menggunakan cara manual. Selain itu banyaknya siswa yang mendaftar setiap tahun, sehingga para guru penilai membutuhkan waktu lebih lama dalam melakukan pemilihan siswa yang lulus dalam pertukaran pelajar. Oleh karena permasalahan tersebut, maka perlu dirancang suatu sistem pendukung keputusan yang hasilnya dapat dijadikan referensi dalam pengambilan keputusan penentuan siswa yang lolos dalam pertukaran pelajar. Metode yang digunakan dalam penelitian ini adalah metode AHP-TOPSIS. AHP digunakan untuk menentukan bobot kriteria dan uji konsistensi, sedangkan TOPSIS digunakan untuk penentuan lulus tidaknya siswa pemilihan pertukaran pelajar sesuai dengan kuota yang ditentukan oleh pengambil keputusan. Kriteria yang digunakan dalam penelitian ini adalah rata-rata nilai raport, kepribadian, pengetahuan budaya, kemampuan seni, wawancara dan tes tulis. Pengujian sistem dilakukan dengan menggunakan 3 pembobotan yang berbeda untuk setiap kriteria dengan membandingkan hasil untuk kriteria tes tulis dan nilai raport menggunakan nilai angka dan juga menggunakan range $(0-49,50-74,75-80)$. Hasil dari perhitungan didapatkan tingkat akurasi terbaik yaitu menunjukkan kecocokan akurasi 100\%. Sehingga bisa dikatakan bahwa hasil dari sistem ini dapat dijadikan referensi bagi pihak SMAN 3 Malang dalam melakukan pemilihan siswa pertukaran pelajar.
\end{abstract}

Kata Kunci : sistem pendukung keputusan, pertukaran pelajar, seleksi siswa, AHP, TOPSIS

\section{Pendahuluan}

Program Pertukaran pelajar memiliki banyak manfaat dari sisi pengetahuan maupun dari sisi personal. Oleh karena banyaknya manfaat yang dirasakan, SMAN 3 Malang sudah sejak lama melakukan program pertukaran pelajar. Namun program ini memiliki beban yang berat karena membawa nama baik bangsa Indonesia, dan juga nama baik sekolah karenanya dibutuhkan pelajar yang berkompeten untuk dapat mengikuti program ini. SMAN 3 Malang memiliki beberapa kriteria dalam penilaian yaitu rata-rata nilai raport, wawancara, tes tulis, pengetahuan budaya, kemampuan seni, dan kepribadian.

Namun cara penilaian yang dilakukan masih menggunakan cara manual. Sistem penilaian seperti ini memiliki kelemahan karena kurangnya objektifitas dalam penilaian serta memungkinkan terjadinya kesalahan penulisan rumus dan perhitungan. Selain itu banyaknya siswa yang mendaftar setiap tahun, sehingga para guru penilai membutuhkan waktu lebih lama dalam melakukan pemilihan siswa yang lulus dalam pertukaran pelajar.
Melihat masalah tersebut, maka dibuatlah Pengembangan Sistem Pendukung Keputusan Pemilihan Siswa Pertukaran Pelajar di SMAN 3 Malang menggunakan Metode AHP-TOPSIS untuk membantu pihak SMAN 3 Malang dalam memilih siswa yang lulus dan tidak dalam pertukaran pelajar.

\section{Tinjauan Pustaka}

\subsection{Sistem Pendukung Keputusan}

Sistem Pendukung Keputusan (SPK) biasanya

dibangun untuk mendukung solusi atas suatu masalah atau suatu peluang. Aplikasi Sistem Pendukung Keputusan digunakan dalam pengambilan keputusan. Aplikasi Sistem Pendukung Keputusan menggunakan CBIS (Computer Based Information Systems) yang fleksibel, interaktif, dan dapat diadaptasi, yang dikembangkan untuk mendukung solusi atas masalah manajemen spesifik yang tidak terstruktur.

\subsection{Pertukaran Pelajar}

Dalam pemilihan siswa pertukaran pelajar di SMAN 3 Malang sudah berlangsung setiap tahun. Setiap tahunnya selalu dilakukan perombakan dan 
perubahan dari sisi kepengurusan, peraturan, negara tujuan pertukaran pelajar, dan kriteria penilaian.

\subsection{AHP}

Metode Analiytical Hierarchy Process (AHP) merupakan sebuah hirarki fungsional dengan input utamanya persepsi manusia. Dengan hirarki, suatu masalah kompleks dan tidak terstruktur dipecahkan salah satu model pengambilan keputusan yang sering digunakan. AHP digunakan dengan tujuan untuk menyusun prioritas dari berbagai alternatif atau pilihan dalam kelompok-kelompok tersebut diatur menjadi suatu bentuk hirarki.

\subsection{TOPSIS}

Technique for Order Preference by Similarity to Ideal Solution (TOPSIS) adalah salah satu metode pengambilan keputusan multikreteria atau alternative pilihan yang merupakan alternative yang mempunyai jarak terkecil dari solusi ideal negative dari sudut padang geometris dengan mengguanakan jarak ecludean. Namun, alternative yang mempunyai jarak terkecil dari solusi ideal positif, tidak harus mempunyai jarak terbesar dari solusi ideal negative.

\section{Metodologi Penelitian}

Metode pengembangan system informasi yang digunakan pada sistem pendukung keputusan Pemilihan Siswa Pertukaran Pelajar di SMAN 3 Malang yaitu menggunakan metode System Development Life Cycle (SDLC) yang biasa disebut dengan model Waterfall. Metode tersebut memiliki beberapa tahapan. Tahapan yang dilakukan yaitu :

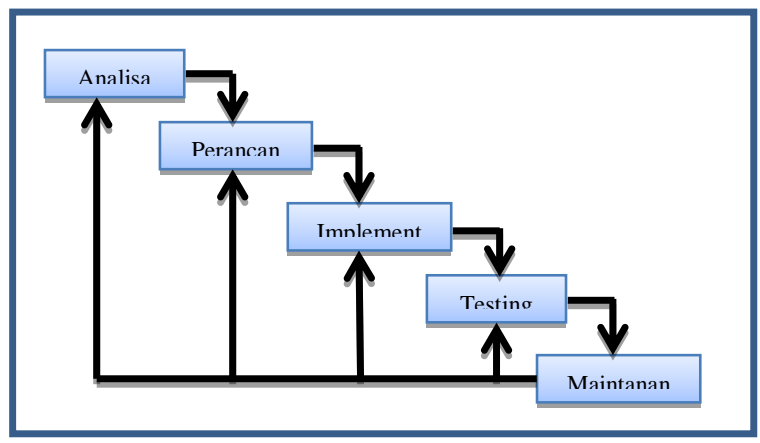

Gambar 1. Tahap Pengembangan Sistem

\subsection{Penerapan Metode AHP-TOPSIS}

Dalam penelitian ini dibutuhkan kriteria dan bobot untuk proses penentuan siswa yang lolos dalam pertukaran pelajar. Adapun kriterianya adalah:
Tabel 3.2 Kriteria Pemilihan Siswa Pertukaran Pelajar

\begin{tabular}{|c|l|}
\hline et & \multicolumn{1}{|c|}{ Kriteria } \\
\hline 1 & Perilaku / Attitude \\
\hline 2 & Rata-rata nilai raport \\
\hline 2 & Pengetahuan Budaya \\
\hline 4 & Kemampuan Seni \\
\hline 5 & Wawancara \\
\hline 6 & Tes Tulis \\
\hline
\end{tabular}

Untuk menghitung bobot dari setiap kriteria menggunakan metode AHP. Cara perhitungannaya sbb:

1. Langkah pertama adalah membuat perbandingan pasangan

Tabel 1. Perbandingan Berpasangan

\begin{tabular}{|l|l|l|l|l|l|l|}
\hline & C1 & C2 & C3 & C4 & C5 & C6 \\
\hline C1 & 1 & 1 & 2 & 2 & 2 & 2 \\
\hline C2 & 1 & 1 & 2 & 2 & 2 & 2 \\
\hline C3 & $1 / 2$ & $1 / 2$ & 1 & 1 & 1 & 2 \\
\hline C4 & $1 / 2$ & $1 / 2$ & 1 & 1 & 1 & 2 \\
\hline C5 & $1 / 2$ & $1 / 2$ & 1 & 1 & 1 & $1 / 2$ \\
\hline C6 & $1 / 2$ & $1 / 2$ & $1 / 2$ & $1 / 2$ & 2 & 1 \\
\hline
\end{tabular}

2. Kemudian menjumlahkan nilai-nilai dari setiap kolom pada matriks.

Tabel 2. Tabel Penjumlahan Kolom

\begin{tabular}{|l|l|l|l|l|l|l|}
\hline & C1 & C2 & C3 & C4 & C5 & C6 \\
\hline C1 & 1 & 1 & 2 & 2 & 2 & 2 \\
\hline C2 & 1 & 1 & 2 & 2 & 2 & 2 \\
\hline C3 & 0.5 & 0.5 & 1 & 1 & 1 & 2 \\
\hline C4 & 0.5 & 0.5 & 1 & 1 & 1 & 2 \\
\hline C5 & 0.5 & 0.5 & 1 & 1 & 1 & 0.5 \\
\hline C6 & 0.5 & 0.5 & 0.5 & 0.5 & 2 & 1 \\
\hline $\begin{array}{l}\text { JML } \\
\text { KOLOM }\end{array}$ & 4 & 4 & 7.5 & 7.5 & 9 & 9.5 \\
\hline
\end{tabular}

3. Membagi setiap nilai kolom dengan total kolom yang bersangkutan untuk memperoleh normalisasi matriks

Tabel 3. Tabel pembagian setiap kolom dengan jumlah

\begin{tabular}{|l|l|l|l|l|l|l|}
\hline & C1 & C2 & C3 & C4 & C5 & C6 \\
\hline C1 & 0.25 & 0.25 & 0.27 & 0.27 & 0.22 & 0.21 \\
\hline C2 & 0.25 & 0.25 & 0.27 & 0.27 & 0.22 & 0.21 \\
\hline C3 & 0.13 & 0.13 & 0.13 & 0.13 & 0.11 & 0.21 \\
\hline C4 & 0.13 & 0.13 & 0.13 & 0.13 & 0.11 & 0.21 \\
\hline C5 & 0.13 & 0.13 & 0.13 & 0.13 & 0.11 & 0.05 \\
\hline C6 & 0.13 & 0.13 & 0.07 & 0.07 & 0.22 & 0.11 \\
\hline
\end{tabular}

4. Menjumlahkan nilai-nilai dari baris dan membaginya dengan jumlah elemen untuk mendapatkan nilai rata-rata. 
Tabel 4. Tabel Penjumlahan Baris

\begin{tabular}{|c|c|c|c|c|c|c|c|}
\hline & C1 & C2 & C3 & C4 & C5 & C6 & $\begin{array}{c}\text { JUMLAH } \\
\text { BARIS }\end{array}$ \\
\hline C1 & 0.25 & 0.25 & 0.27 & 0.27 & 0.22 & 0.21 & 1.47 \\
\hline C2 & 0.25 & 0.25 & 0.27 & 0.27 & 0.22 & 0.21 & 1.47 \\
\hline C3 & 0.13 & 0.13 & 0.13 & 0.13 & 0.11 & 0.21 & 0.84 \\
\hline C4 & 0.13 & 0.13 & 0.13 & 0.13 & 0.11 & 0.21 & 0.84 \\
\hline C5 & 0.13 & 0.13 & 0.13 & 0.13 & 0.11 & 0.05 & 0.68 \\
\hline C6 & 0.24 & 0.21 & 0.30 & 0.30 & 0.20 & 0.23 & 1.49 \\
\hline
\end{tabular}

5. Kalikan setiap nilai pada kolom pertama dengan prioritas relatif elemen pertama, nilai pada kolom kedua dengan prioritas relatif elemen kedua, dan seterusnya.

Tabel 5. Tabel Perkalian menghasilkan Eigen

\begin{tabular}{|c|c|}
\hline $\begin{array}{l}\text { EIGEN VEKTOR } \\
\text { NORMALISASI }\end{array}$ & $\begin{array}{l}\text { JUMLAH } \\
\text { KOLOM } \\
\text { MATRIX } \\
\text { PAIRWISE }\end{array}$ \\
\hline 0.24434698 & 4 \\
\hline 0.24434698 & 4 \\
\hline 0.13971735 & 7.5 \\
\hline 0.13971735 & 7.5 \\
\hline 0.11340156 & 9 \\
\hline 0.11846979 & 9.5 \\
\hline
\end{tabular}

6. Jumlahkan hasil setiap baris sehingga mendapatkan nilai eigen max

Tabel 6. Penjumlahan Eigen

\begin{tabular}{|c|}
\hline EIGEN MAX \\
\hline 0.977 \\
\hline 0.977 \\
\hline 1.048 \\
\hline 1.048 \\
\hline 1.021 \\
\hline 1.125 \\
\hline 6.2 \\
\hline
\end{tabular}

7. Mengukur Konsistensi

Menghitung Consistency Index (CI), dengan rumus :

$$
\begin{aligned}
& \mathrm{CI}=(\lambda \text { maks }-\mathrm{n}) / \mathrm{n}-1 \\
& \mathrm{CI}=(6.2-6) / 6-1 \\
& \mathrm{CI}=(6.2-6) / 5 \\
& \mathrm{CI}=0.04
\end{aligned}
$$

Dimana $\mathrm{n}$ adalah banyaknya kriteria.

Menghitung Consistency Ratio (CR) dengan persamaan

$$
\begin{aligned}
& \mathrm{CR}=\mathrm{CI} / \mathrm{IR} \\
& \mathrm{CR}=0.04 / 1.24 \\
& \mathrm{CR}=0.0317
\end{aligned}
$$

IR adalah Indeks Random Consistency. Indeks Random Consistency merupakan nilai yang sudah ditentukan sesuai dengan jumlah kriteria. Karena kriteria yang digunakan berjumlah 6 makan nilai IR 1,24.

8. Jika $\mathrm{CR}<0,1$ maka nilai perbandingan berpasangan pada matriks kriteria yang diberikan konsisten. Jika $\mathrm{CR}>=0,1$, maka nilai perbandingan berpasangan pada matrik kriteria yang diberikan tidak konsisten.

\subsection{Perhitungan TOPSIS}

Sebelum melakukan perhitungan, terlebih dahulu melakukan konversi nilai seperti tabel dibawah ini

\begin{tabular}{|c|c|c|c|c|c|c|}
\hline \multirow[t]{2}{*}{ ВОВОт } & 0.09 & 0.12 & 0.10 & 0.40 & 0.24 & 0.06 \\
\hline & $\begin{array}{c}\text { BENE } \\
\text { FIT }\end{array}$ & $\begin{array}{c}\text { BENE } \\
\text { FIT }\end{array}$ & $\begin{array}{l}\text { BEN } \\
\text { EFIT }\end{array}$ & $\begin{array}{c}\text { BENE } \\
\text { FIT }\end{array}$ & $\begin{array}{c}\text { BENE } \\
\text { FIT }\end{array}$ & $\begin{array}{c}\text { BENE } \\
\text { FIT }\end{array}$ \\
\hline SISWA & C1 & C3 & C4 & C5 & C6 & C2 \\
\hline 1 & 4 & 4 & 4 & 5 & 90 & 88 \\
\hline 2 & 3 & 5 & 5 & 5 & 90 & 87 \\
\hline 3 & 3 & 5 & 5 & 5 & 90 & 89 \\
\hline
\end{tabular}

Tabel 7. Data Asli

\begin{tabular}{|c|c|c|c|c|c|c|}
\hline SISWA & C1 & C3 & C4 & C5 & C6 & C2 \\
\hline 1 & 85 & 85 & 85 & 90 & 90 & 88 \\
\hline 2 & 80 & 86 & 86 & 90 & 90 & 87 \\
\hline 3 & 80 & 90 & 86 & 86 & 90 & 89 \\
\hline
\end{tabular}

Tabel 8. Range nilai

\begin{tabular}{|l|l|}
\hline \multicolumn{2}{|c|}{ Range Nilai } \\
\hline Nama Range & Nilai \\
\hline Sangat Baik & $86-100$ \\
\hline Baik & $81-85$ \\
\hline Cukup & $75-80$ \\
\hline Buruk & $50-74$ \\
\hline Sangat Buruk $0-49$ \\
\hline
\end{tabular}

Sehingga didapatkan data seperti pada tabel 9.

Tabel 9. Hasil Konversi

a. Pertama membuat matrik keputusan yang ternomalisasi dengan rumus:

$$
\mathbf{r i j}=\frac{X i j}{\sqrt{\sum_{i}^{m}=X^{2} i j}}
$$

Sehingga menghasilkan

Tabel 10. Tabel Normalisasi

\begin{tabular}{|l|l|l|l|l|l|l|}
\hline & 0.685994 & 0.492366 & 0.492366 & 0.57735 & 0.57735 & 0.577325 \\
\hline $\mathrm{R}=$ & 0.514496 & 0.615457 & 0.615457 & 0.57735 & 0.57735 & 0.570765 \\
\hline & 0.514496 & 0.615457 & 0.615457 & 0.57735 & 0.57735 & 0.583886 \\
\hline
\end{tabular}

b. Membuat matrik keputusan normalisasi terbobot.

$$
\text { Vij }=\text { wj. rij }
$$

Sehingga Menghasilkan

Tabel 11. Tabel Normalisasi Terbobot

\begin{tabular}{|l|l|l|l|l|l|l|}
\hline & 0.081290 & 0.068784 & 0.068784 & 0.141047 & 0.141047 & 0.065469 \\
\hline $\mathrm{Y}=$ & 0.060968 & 0.085979 & 0.085979 & 0.141047 & 0.141047 & 0.064725 \\
\hline & 0.060968 & 0.085979 & 0.085979 & 0.141047 & 0.141047 & 0.066213 \\
\hline
\end{tabular}

c. Menentukan matrik solusi ideal positif dan solusi ideal negative. Solusi ideal positif $=$ A+, solusi ideal negative A-

$\mathbf{A}^{+}=\left\{\left(\max V i j|j| \mathbf{j}^{\prime}\right),\left(\min V \mathbf{i j} \mid \mathbf{J} \epsilon \mathbf{J}^{\prime}\right), \mathbf{i}=\mathbf{1}, \mathbf{2}, \mathbf{3} \ldots \mathbf{m}\right\}$ $=\left\{\mathbf{V}_{1}, \mathbf{V}_{2}, \mathbf{V}_{3} \ldots . . . \mathrm{Vn}\right\}$ 
$A^{-}=\left\{\left(\min V i j \mid j \epsilon \mathbf{j}^{\prime}\right),\left(\max V i j \mid ~ J \epsilon J^{\prime}\right), \mathbf{i}=1,2,3 \ldots . . m\right\}$ $=\left\{\mathbf{V}_{1}, \mathbf{V}_{2}, \mathbf{V}_{3} \ldots . . . \mathrm{Vn}\right\}$

Tabel 12. Tabel Normalisasi

\begin{tabular}{|l|r|r|r|r|r|r|}
\hline A+ & 0.08129 & 0.085979 & 0.085979 & 0.141047 & 0.141047 & 0.066213 \\
\hline A- & 0.060968 & 0.068784 & 0.068784 & 0.141047 & 0.141047 & 0.064725 \\
\hline
\end{tabular}

d. Menghitung separasi

$$
\mathbf{S i}^{+}=\sqrt{\sum_{\mathrm{j}}^{\mathrm{n}}=1}(\mathrm{Yij}-\mathrm{Aj}+)^{2}
$$

Hasil perhitungan Jarak Ideal Positif yaitu

Tabel 13. Tabel Jarak Ideal Positif

\begin{tabular}{|c|c|}
\hline SISWA & D+ \\
\hline 1 & 0.02433 \\
\hline 2 & 0.020377 \\
\hline 3 & 0.020323 \\
\hline
\end{tabular}

$$
\begin{aligned}
& \mathbf{S i}^{-}=\sqrt{\sum_{j}^{n}=1}\left(Y_{i j-A j-}\right)^{2} \\
& \text { Hasil perhitungan Jarak Ideal negatif yaitu }
\end{aligned}
$$

Tabel 14. Tabel Jarak Ideal Negatif

\begin{tabular}{|c|c|}
\hline SISWA & D- \\
\hline 1 & 0.020336 \\
\hline 2 & 0.024319 \\
\hline 3 & 0.024364 \\
\hline
\end{tabular}

e. Menghitung kedekatan terhadap solusi ideal postif

$$
\mathbf{V i}=\frac{S i-}{(S i-+S i+)}
$$

Tabel 15. Tabel Kedekatan Terhadap Solusi Ideal

\begin{tabular}{|c|c|}
\hline & HASIL \\
\hline V1 & 0.455292 \\
\hline V2 & 0.544095 \\
\hline V3 & 0.545221 \\
\hline
\end{tabular}

f. Merangking alternative

Tabel 16. Tabel Rangking Setiap Alternatif

\begin{tabular}{|c|c|c|}
\hline SISWA & HASIL & Rangking \\
\hline 1 & 0.455292 & 3 \\
\hline 2 & 0.544095 & 2 \\
\hline 3 & 0.545221 & 1 \\
\hline
\end{tabular}

\section{Analisis dan Perancangan}

\subsection{Gambaran Umum Sistem}

Sistem Pendukung Keputusan Pemilihan siswa pertukaran pelajar adalah sistem yang dibangun untuk membantu pihak SMAN 3 Malang dalam memilih siswa yang lulus dalam pertukaran pelajar. Sistem ini akan mempermudah guru penilai dalam melakukan penilaian dan mempermudah admin dalam mempermudah proses seleksi.

\subsection{Use Case Diagram}

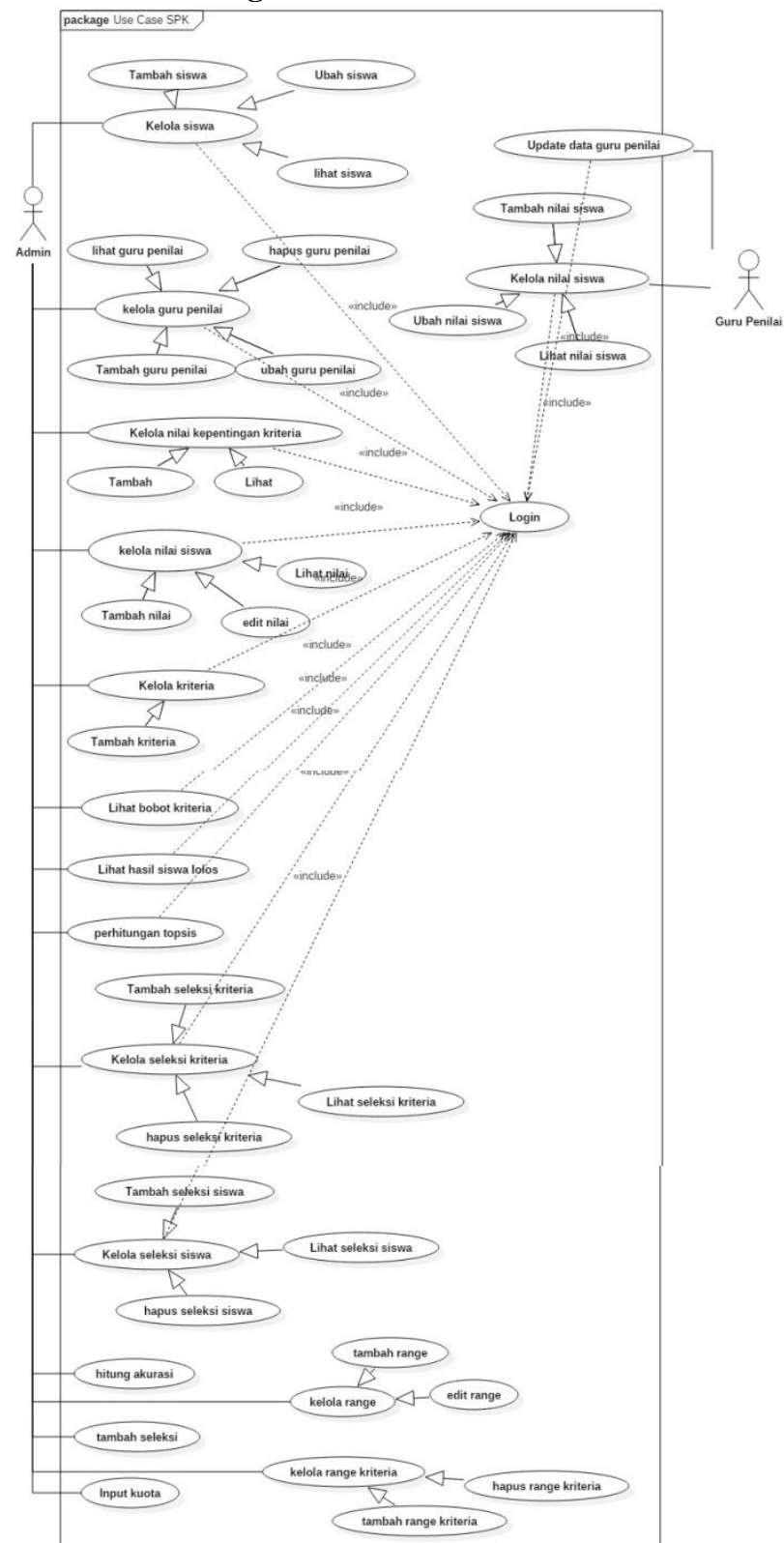

Gambar 2. Use Case SPK Pemilihan Siswa Pertukaran Pelajar

Pada gambar diatas terdapat 2 aktor yang terdiri dari admin dan guru penilai, admin bertugas untuk melakukan proses seleksi mulai dari menambahkan seleksi, kriteria, menghitung bobot, menambahkan siswa dan melakukan seleksi pemilihan siswa yang lulus dalam pertukaran pelajar. Sedangkan guru penilai melakukan penilaian siswa dan melihat hasil siswa yang lulus dalam pertukaran pelajar.

Berikut ini merupakan class diagram SPK Pemilihan Siswa Pertukaran Pelajar: 


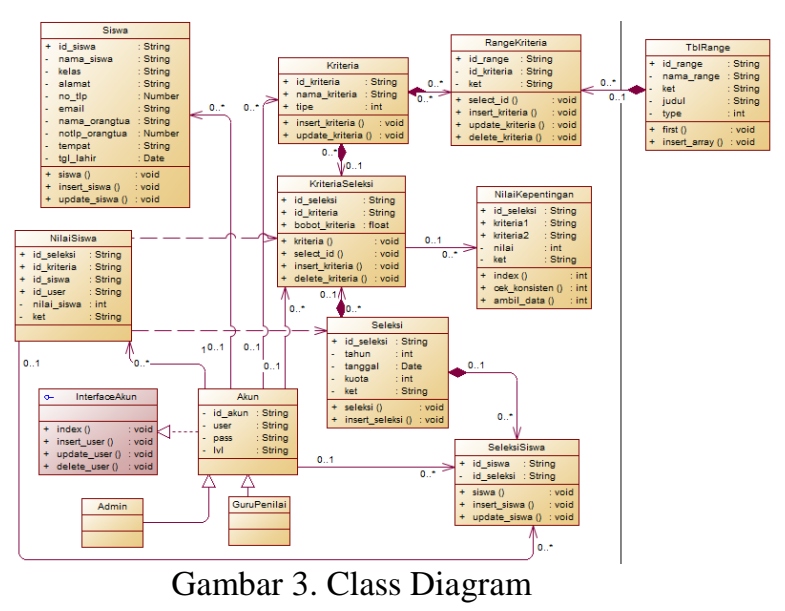

5. Implementasi

5.1 Implementasi Basis Data

Basis data yang digunakan dalam pengembangan sistem pendukung keputusan pemilihan siswa pertukaran pelajar menggunakan XAMPP. Dalam pembuatan sistem diperlukan database untuk menyimpan data-data yang ditambahkan, diubah, dihapus, maupun ditampilkan oleh sistem. Basis data yang digunakan dalam pemilihan siswa pertukaran pelajar terdapat 10 tabel yaitu, tabel seleksi_siswa, seleksi, kriteria_seleksi, kriteria, range kriteria, siswa, nilai_kepentingan, tblrange, nilai_siswa, dan akun.

\subsection{Implementasi Proses dan Antarmuka}

Dalam sistem pendukung keputusan ini penulis menggunakan bahasa pemrograman PHP dengan framework CodeIgniter sehingga dalam implementasi source code dan antarmuka dibagi menjadi 3 yaitu model, view, dan controller. Pada implementasinya system pendukung keputusan pemillihan siswa pertukaran pelajar ini terdapat 1 model, 18 controller, dan puluhan view.

\section{Pengujian}

Pengujian pada sistem ini meliputi beberapa jenis pengujian, yaitu pengujian fungsional, pengujian validasi, dan pengujian akurasi.

\subsection{Pengujian Fungsional}

Menurut pengujian sistem yang telah dilakukan, fungsi-fungsi dalam sistem ini telah berjalan sesuai perencanaan dengan akurasi $100 \%$.

\subsection{Pengujian Validasi}

Berdasarkan pengujian yang dilakukan, perbandingan perhitungan dengan cara manual dan dengan sistem menghasilkan nilai yang sama sehingga memiliki akurasi $100 \%$.

\subsection{Pengujian Akurasi}

Pengujian akurasi dilakukan dengan cara mencocokkan data hasil keputusan system tahun 2015 dengan data hasil seleksi pemilihan siswa pertukaran pelajar pada hasil sebenarnya. Untuk mendapatkan hasil akurasi yang terbaik terdapat 2 skenario dalam melakukan pengujian, skenario pertama yaitu membandingkan 3 bobot kriteria tanpa menggunakan range kriteria pada kriteria nilai raport dan tes tulis, skenario kedua yaitu membandingkan 3 bobot kriteria dengan menggunakan range kriteria pada kriteria nilai raport dan tes tulis.

Hasil pengujian dengan menggunakan skenario yang sudah ditentukan ditunjukkan pada gambar 4 .

\begin{tabular}{|c|c|c|c|c|}
\hline \multicolumn{2}{|c|}{ Nilai } & \multicolumn{3}{c|}{ Data Bobot } \\
\cline { 3 - 5 } & BOBOT 1 & BOBOT 2 & BOBOT 3 \\
\hline $\begin{array}{c}\text { Tampa } \\
\begin{array}{c}\text { Menggunakan } \\
\text { range kriteria }\end{array}\end{array}$ & $\begin{array}{c}\text { Hasil Uji Status } \\
\text { Kelulusan (\%) }\end{array}$ & 100 & 95,56 & 95,56 \\
\hline $\begin{array}{c}\text { Menggunakan } \\
\text { range kriteria }\end{array}$ & $\begin{array}{c}\text { Hasil Uji Status } \\
\text { Kelulusan (\%) }\end{array}$ & 95,56 & 91,11 & 91,11 \\
\hline
\end{tabular}

Gambar 4. Data Hasil Matriks Perbandingan

Dari hasil pengujian diatas akan menghasilkan grafik seperti pada gambar 5 .

\section{Hasil Pengujian Berdasarkan Skenario}

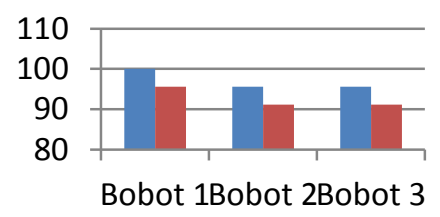

\author{
Status \\ Kelulusan \\ (Tanpa range \\ kriteria)
}

Gambar 5. Grafik perbandingan ujicoba akurasi

Dari hasil pengujian 2 skenario yang memiliki tingkat kecocokkan tertinggi adalah pada bobot yang ke-1 tanpa menggunakan range kriteria pada kriteria nilai raport dan tes tulis dengan tingkat kecocokkan uji status kelulusan sebesar $100 \%$.

Dari pengujian skenario tersebut, diilihat hasil uji coba status kelulusan menunjukkan tingkat kecocokan tinggi,. Hal ini disebebakan oleh beberapa kemungkinan yaitu perbedaan bobot kriteria, penilaian menggunakan range kriteria dan juga tidak menggunakan range kriteria, rumus perhitungan dalam memilih siswa pertukaran pelajar yang berbeda. yang dilakukan di SMAN 3 Malang.

\section{Kesimpulan}

7.1 Kesimpulan

Aplikasi sistem pendukung keputusan pemilihan siswa pertukaran pelajar di SMAN 3 malang dengan menggunakan metode AHP-TOPSIS telah dibangun sesuai dengan perancangan. Pengujian hasil sistem dengan hasil sebenarnya menunjukkan akurasi kecocokan $100 \%$. Sehingga bisa dikatakan bahwa 
sistem dapat digunakan untuk melakukan penilaian secara terkomputerisasi dan dapat memberikan referensi kepada pihak SMAN 3 Malang dalam pengambilan keputusan siapa yang lulus dalam pemilihan siswa pertukaran pelajar.

\subsection{Saran}

Sistem Pendukung Keputusan Pemilihan Siswa Pertukaran Pelajar di SMAN 3 Malang dengan Metode AHP- TOPSIS untuk pengembangannya diharapkan sistem ini dapat dikembangkan dengan teknologi terbaru yang ada sehingga dapat dimanfaatkan untuk pemilihan siswa pertukaran pelajar dengan menggunakan kriteria yang berbeda pula.

\section{Daftar Pustaka:}

Aniq, M., (2016): Narasumber Panitia Pemilihan Siswa Pertukaran Pelajar Di SMAN 3 Malang.

Arfani, A. Y., dkk., (2013): Analisa Perbandingan Metode Gabungan AHP Dan TOPSIS Dengan Metode TOPSIS, Teknik Informatika Universitas Gorontalo.

Azmi, M., (2014): Pemanfaatan Sistem Pendukung Keputusan Untuk Penentuan Alokasi Dana Kegiatan (Studi Kasus Unit Kegiatan Mahasiswa Politeknik Negeri Padang), ISSN : 1693-752X

Kusrini, (2007): Konsep dan Aplikasi Sistem Pendukung Keputusan, Yogyakarta, Andi Offset.

Nofriansyah, D., (2014): Konsep Data Mining Vs Sistem Pendukung Keputusan, Yogyakarta, Deepublish

Sofwan, A., (2007): Belajar PHP dengan Framework Code Igniter, [Online] Tersedia: http://www.sofwan.net 2007, [1 Desember 2015]

Suryadi, K.., \& Ramdhani, M. A., (1998): Sistem Pendukung Keputusan Suatu Wacana Struktural Idealisasi Dan Implementasi Konsep Pengambilan Keputusan, Bandung, PT Remaja Rosdakarya.

Trianto, R. B., Penentuan Peminatan Peserta Didik Menggunakan Metode AHP-TOPSIS (Studi Kasus SMA Negeri 6 Semarang)

Wicaksono, D., (2013): Sistem Pendukung Keputusan Penentuan Beasiswa Supersemar di SMKN 3 Semarang dengan Metode TOPSIS dan AHP

Yoon, K., \& Hwang, C. L., (1981): Multiple Attribute Decision Making: Methods and Applications, Berlin, Springer. 